\title{
Erratum to: The Electron Drift Instrument for MMS
}

\author{
R.B. Torbert ${ }^{1,2}$ - H. Vaith ${ }^{1}$ M. Granoff ${ }^{1}$ - M. Widholm ${ }^{1}$ - J.A. Gaidos ${ }^{1}$ - B.H. Briggs ${ }^{1}$

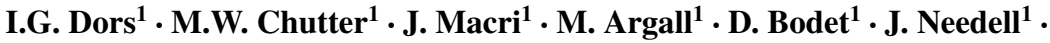 \\ M.B. Steller ${ }^{3}$ - W. Baumjohann ${ }^{3}$ - R. Nakamura ${ }^{3}$ - F. Plaschke ${ }^{3} \cdot$ H. Ottacher ${ }^{3}$. \\ J. Hasiba ${ }^{3}$ - K. Hofmann ${ }^{3}$ C.A. Kletzing ${ }^{4}$ - S.R. Bounds ${ }^{4}$ - R.T. Dvorsky ${ }^{4}$ K. Sigsbee $^{4}$ \\ V. Kooi ${ }^{4}$
}

Published online: 10 February 2016

(C) Springer Science+Business Media Dordrecht 2016

Erratum to: Space Sci. Rev. (2016)

DOI 10.1007/s11214-015-0182-7

Section 3.3, Eq. (4): " $B$ " should be in the denominator. Please find in this erratum the correct version of Eq. (4) in Sect. 3.3 that should be regarded by the reader as the final version.

\subsection{Measurement of $B$}

The gyro period can be obtained from the mean of two the travel times, one "toward" and one "away" from the target, as described above:

$$
T_{g}=\frac{t_{1}+t_{2}}{2}
$$

From $T_{g}$ the magnetic field strength, $B$, is obtained via

$$
T_{g}=\frac{2 \pi m \gamma}{e B}
$$

The online version of the original article can be found under doi:10.1007/s11214-015-0182-7.

$凶$ R.B. Torbert

roy.torbert@unh.edu

1 University of New Hampshire, Durham, NH 03824, USA

2 Southwest Research Institute, San Antonio, TX 78227, USA

3 Space Research Institute, 8042 Graz, Austria

4 University of Iowa, Iowa City, IA 52242, USA 
Values of $T_{g}$ range from about 0.1 to $5 \mathrm{~ms}$ (see Table 2). The method is sensitive enough to require the relativistic $\gamma$ correction even for a $500 \mathrm{eV}$ electron. When times of flight are measured, the magnetic field strength is determined with very high accuracy, e.g., to within $0.1 \%$ for a $30 \mathrm{nT}$ field. This feature is used for an accurate in-flight determination of the fluxgate magnetometer offsets. 